to the high speed at which the airships move, such quick movements are one of the features which need to be especially designed in the case of guns for balloon firing. The weight of the gun itself, or 990 pounds, combined with the weight of the support, 1,550 pounds, gives a total weight of 2,540 pounds for this type of gun. We have here the maximum angle which is reached in the Krupp cannon, or 75 degrees. The weight of the projectile is 12 pounds, and the initial speed 2,060 feet per second. The maximum range is about 30,000 feet, and the greatest height about 20,000 feet. As regards the automobile car which is designed to take the present cannon, its total weight (exclusive of the gun) is $3 \frac{1 / 2}{2}$ tons, and it has an average speed of 30 miles an hour.

Owing to the fact that both axles are driving axles, with the use of 50 horse-power motor the automobile car is able to travel over very difficult ground, and it easily mounts very steep grades. Under the front sea is a roomy chest which holds a good supply of tools and extra fittings, and special attention has been given to this point so that the car will not easily become disabled. To make the platform of the car as steady as possible during the firing, the platform is clamped tight against the axles. The third type of cannen is of much heavier build than the two which precede, seein that in this case it is designed to be mounted on shipboard, and hence the weight does not need to be re duced as in the other cases. It is of a considerably larger caliber, this being 10.5 centimeters ( 4.2 inches) In most of the details it is designed on the same line as the second type. It is intended to be mounted generally upon torpedo boats or swift cruisers and nat urally the gun can be brought into service as an ord nary cannon in cases where it is needed. For the gun proper, the weight is 3,080 pounds, while the support weighs 3,520 pounds, giving a total weight of 6,600 pounds for this type. Like the former, the angle of elevation is 75 degrees at a maximum. The projectile, weighing 40 pounds, has an initial speed of 2,300 feet per second. A horizontal range of 44,500 feet is reached, and we have the unusual height of 37,620 feet.

The present types of gun have been given a series of tests by firing upon captive balloons, and while the practice on these may be considered fairly satisfactory, it cannot be considered as anything more than experimental, and the results are only applicable to the particular conditions of the experiment.

In actual warfare the captive balloon would seldom require consideration, and the real value of these new classes of ordinance lies in their effectiveness against big airships provided with guns and bombs and the fast aeroplanes of the scout or bomb-dropper, and for this work results with the new guns are yet to be shown.
Exploding Mines by Wireless Telegraphy By Dr. Charles Forbes, Columbia University, N. Y. THE newspaper accounts that have appeared from time to time in regard to the explosion of submarine mines by means of radio-telegraphy might lea the ordinary reader to believe there is danger of exploding powder magazines on war vessels, and torpedoes internal ends of the rods is to be nearly filled with filings of nickel about 9 parts and silver 1 part. If the pure metals are not available for the filings nickel and silver coins may be substituted. A trace of mercury, which is desirable, may be secured by amalgamating the internal ends of the rods in the glass tube. 'The coherer has this peculiar property: the filings, in the inactive

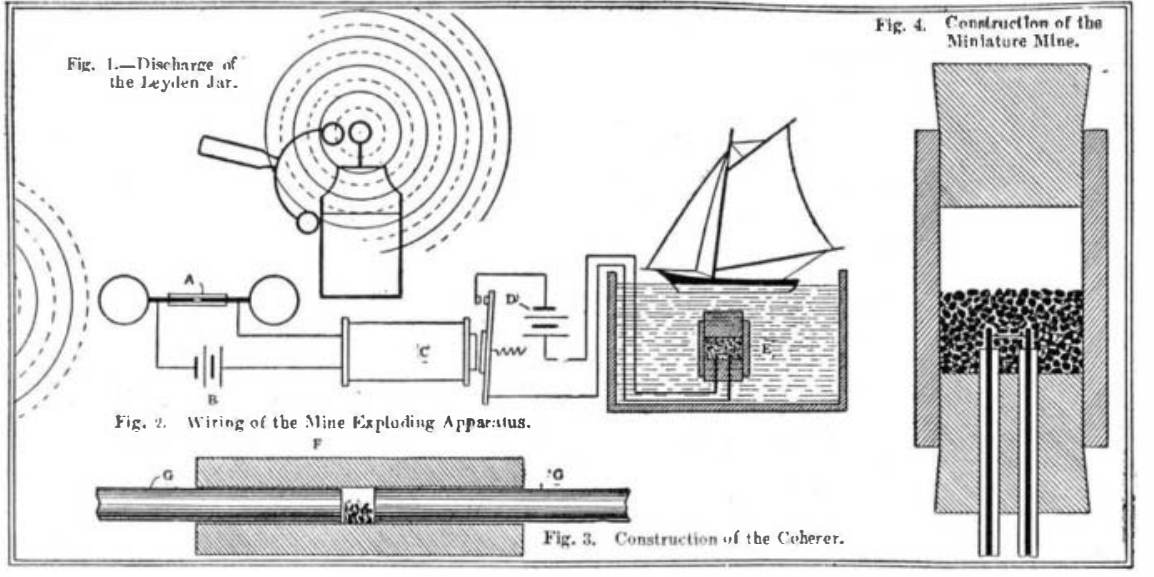

Experimental apparatus used to illustrate the exploding of a submarine mine by wireless telegraphy.

and mines located in harbor's for defense, in the daily use of the wireless telegraph. Such an event cannot, however, take place without the intervention of apparatus specially constructed for the purpose.

An interesting laboratory experiment illustrative of the subject may be performed as follows: 'There must be apparatus for generating the electric waves, known as the Hertzian, from their discoverer'; also apparatus for receiving the impressions produced by them. Like for receiving the impressions produced by them. Like
the telegraph and telephone the transmitting and the receiving instruments are essential. For the laboratory experiment the transmitting apparatus may consist of the usual amateur outfit. In the absence of this the sparks from an influence electrical machine, the induction coil or the Leyden jar will be sufficient to set up the Hertzian waves. In the simplest form the Leyden jar answers the purpose very well. The receiving apparatus consists of the Branly coherer, which is placed in series with a suitable electric battery, two dry cells being sufficient, and a relay, which in action closes a second electric circuit generated by another battery of two dry cells. This current is conducted by communicating wires to the exploding fuse in the mine to be exploded.

Inspection of the illustration will show the wiring and the arrangement of the apparatus for the laboratory experiment. Fig. 1 represents the Leyden jar being discharged by the discharging rods. Electric waves are represented passing outward in all directions ready to impinge upon receiving apparatus situated in their path. Fig. 2 represents the receiving apparatus. The coherer is at $A$, the battery at $B$, the relay at $C$, the relay battery at $D$, and the mine to be exploded at $E$, resting in a tank of water.

On discharging the Leyden jar, this is what takes place: The electric waves thereby generated pass onward through space, and acting on the coherer, its battery is set in operation, thereby closing the relay circuit, which in turn actuates the fuse, when the explosion of the mine is effected.

The essential part of the receiving apparatus is the coherer. The details of its construction are represented in Fig. 3. A glass tube about 2 inches in length is represented at $F$. Into this there are fitted, rather snugly, brass or copper rods $G$; the internal ends being separated about one eighth of an inch and the external ends having metal disks attached, somewhat larger than those represented in Fig. 2. The space between the ratus would also be necessary. condition, offer a ligh resistance to the passage of a battery current of electricity; when acted upon by the electric waves they are said to cohere, offering much less resistance, thereby allowing a much greater electrlc current to pass. This is sufficient to actuate the relay. The miniature mine to be exploded is represented ia Fig. 4, about the actual size. It consists of a metal tube with a rubber stopper inserted at its upper end and another at the lower end. Through the lower stopper the insulated conducting wires from the relay battery pass. The terminals are connected by a fine iron or platinum wire, which is imbedded in the gun powder in the inclosed chamber. The fine wire on becoming incandescent ignites the powder and the explosion takes place. Interest will be added to the experiment if, preceding the explosion of the miniature mine, the closure of the relay current be made to ring an electric door bell, and if by tapping the coherer, the ringing may be discontinued. In a similar manner electric lights may be lighted on substituting the electric light eurrent for the relay battery current. In actual practice the sending apparatus of the wireless telegraph would be used to set the ether waves in motion and the submarine mine would be attached directly or indirectly to the receiving apparatus. From the above described experiment, it is quite evident that the accidental explosion of mines and other magazines of explosives by means of the Hertzian waves is very improbable. An explosion by electrical induction would be a very different thing, and could only take place at a distance of a few feet. For its occurrence, specially arranged appa-

\section{The Other Side of War}

BY this caption Dr. E. Helme, writing in Le Temps, means to indicate the rougher side with which those individuals come into painful contact who feel within their own skins the effects of modern weapons. To the question: Will war be more murderous in the future? this expert answers with an unhesitating affirmative. Wars, it is true, instead of lasting a hundred, thirty, or seven years, as in bygone days, now last only a few months. But this, he says, simply means that the blows are heavier, and the combatants are sooner exhausted. The Russo-Japanese war lasted only - eighteen months, but the battle of Sha Ho, in Manchuria, consumed twelve days. Thus, although the number of killed and wounded per day in the actual fghting of the Franco-German war may have been greater, the losses in battle in the Manchurian campaigl were much greater in the aggregate. The truly terrible fact, however, is the increasing proportion of mortal to non-mortal wounds: In the l'ranco-German war of 1870-71, the victorious army lost ten men killed to ever 58 wounded; in 1904-05 there were ten Japanese killed to every 37 wounded.

Coming to the explanation of these facts, Dr. Helme dismisses as "a troublesome legend" the story that modern bullets, being smaller and moving more rapidly, inflict less serious wounds. Really slight wounds, he maintains, heal more quickly and more thoroughly nowadays than formerly; but the severe wounds are no less severe and much more frequent. To illustrate this the writer considers, first, the form and structure of projectiles and then their motions. "The lance wol luandled inflicts severe abdominal wounds," and the Japanase cut-and-thrust bayonet "is terrible"; but the writer's main theme is the effect of projectiles.

First comes the rifle bullet, "but yesterday the Queen Murderess of Battles." The German bullet consists of a core of lead lardened with antimony, covered with a steel jacket. It is none the less efficacious becaus the jacket often comes off and acts on its own accoun as a jagged fragment of metal, lacerating the human body. The Irench bullet, thougl not jacketed, is no linder to the enemy. It is louger and shirper-pointed than the Germian, and is made of a mixture of copper and zinc. Becoming bent by ricochetting, it sometimes enter's its victim's body in the shape of a hook; some times it "tumbles" in its flight, enters broadside-on, and makes a long, gaping wound. Up to a range of 800 meter's these rival horrors are one as bad as the other.

The gravity of the wounds depends on a multitude of conditions. On the rocks of San Juan, where the ballets ricochetted in wonderful fashion, the American surgeons reported frightful injuries. It was the same at Spion Kop, in the Transvaal. It used to be said, optimistically, that a bullet heated by friction in the barrel of the rifle would reach its object asepticized by friction; but this hope has been dispelled by the researches of von Koler, showing that the temperature of the projectile never comes within many degrees of that which is necessary for the destruction of microbes. The cruelty of the moder'n bullet has been augmented, too, with the increase of its rotation, so that it acts not only as a club, striking a heavy blow, and a perforating point, but also as a gimlet which lacerates the tissues.

But bullets, after all, are mild agents of destruction when compared with up-to-date shells. The shel wounds in the war of 1870 were only 91 per thousand; in the Manchurian campaign they were 176 per thousand; in the Balkan war of 1912 they were four times as numerous as in 1870 . The shrapnel shell has the advantage (to its employer) of scattering destruction by means of some hundreds of small round bullets as well as the fragments of the shell itself. This "devil's watering-pot," as the Russian soldiers called it, works best within a radius of 10 to 30 meters; at 100 meters its "dewdrops" are still lively enough to penetrate 6 centimeters of pine board; at 300 meters a turban will protect the head from their effects. The tortuous in cisions made by shrapnel are particularly difficult to disinfect. But in spite of all this, and though the ear of the most hardened veteran is said never to become accustomed to the death-song of shraprel overhead, the common shell is really more terrible. Its fragments, brought to a very high temperature by the explosion, "burn the flesh so as to compel cries of agony which only morphine can quiet." Lastly, the large shells of the naval guns "not only cut like razors, but asphyxiate, amputate portions of the body and crush."

Dr. Helme's study of the movement of projectiles and its effects at various ranges, and on various tis- 